\title{
Discontinuity and Discourse Structure: Stranded Nominals as Asserted Background Topics
}

\author{
Eric Mathieu \\ University of Ottawa \\ emathieu@uottawa.ca
}

\begin{abstract}
The aim of this paper is to investigate Rizzi's (2001) recent claim that in combien constructions full movement correlates with a specific or D-linking interpretation of the nominal (see also Obenauer, 1994) while the in-situ option corresponds to focus of the noun. On the one hand, it is argued that the notion of specificity or D-linking for the raised nominal is too strong while on the other hand it is shown that the stranded nominal is not a focus, but a topic, albeit of a special kind. It is also argued that there is a dedicated postverbal position for this kind of topic and that the nominal has all the properties of an incorporated nominal: it is interpreted as an asserted background topic. In the final part of the article, some time is spent discussing the pragmatics and the modality involved in discontinous structures, and showing that the stranded nominal is interpreted inside the VP/below the event variable.
\end{abstract}

\section{Introduction}

As is well-known, it is possible in French to split combien de constructions, as illustrated in (1a), (1b) being the non-split alternative (cf. Doetjes 1997; Obenauer 1976, 1983, 1994; Rizzi 1990; de Swart 1992; for a recent theory of split constructions in semantic terms, see Butler \& Mathieu 2004).

(1) a. [CP Combien ${ }_{\mathrm{i}}$ as-tu lu $\left[\mathrm{DP}_{\mathrm{i}}\right.$ de livres $\left.]\right]$ ? how-many have-you read of books

b. [CP [DPCombien de livres $] \mathrm{i}$ as-tu lus $\left.\mathrm{t}_{\mathrm{i}}\right]$ ? how-many of books have-you read.MAS.PL

'How many books have you read?'

Of particular interest to us is Rizzi's (2001) recent claim that in such constructions full movement correlates with a specific or D-linking interpretation of the nominal that is associated with combien (see also Obenauer 1994) while the split variant correlates with a focus interpretation of the nominal.

The aim of the present article is to investigate this claim. It is shown that the contention that the nominal is specific or D-linked is too strong. Instead, it 
is argued that the main characteristic of the fronted nominal is that it is foregrounded (no presupposition or D-linking is thus necessarily involved). On the other hand, it is shown that, although it is clear the remnant nominal receives default nuclear stress, it is not focused in the traditional sense of the term. Rather, it is an asserted background topic in the sense of Chierchia \& McConnell-Ginet (2000). The present paper builds on previous work of mine (e.g. Mathieu 2004) by adding new material and by extending the discussion on the foreground/background dichotomy as well as concentrating on the asserted background nature of the topic nominal. In addition, particular attention will be paid to the modality and event semantics involved in discontinuous structures.

The paper is organised as follows. In section 2 the syntactic and semantic properties of incorporated nominals (henceforth, INs) are reviewed. Section 3 turns to the case of stranded nominals (henceforth, SNs) in split combien constructions and shows that they share many syntactic and semantic properties with those of INs. In section 4, a summary of the various approaches to semantic incorporation are introduced while in section 5 a formal account of the syntactic and semantic properties of SNs is given. The conclusion can be found in section 6 .

\section{The Syntactic and Semantic Properties of INs}

In this section, we go through the various syntactic and semantic properties of INs. Beginning with syntactic properties, it has been shown that whereas nonincorporation of the nominal is accompanied by rich agreement on the verb and on the noun, in the case of incorporation of the noun no such agreement is available. The term anti-agreement will be used for this phenomenon. To illustrate, consider the following two examples from West Greenlandic. In (2a) the noun has no Case or number marking and the verb lack person and number marking corresponding to the object parcel. However, in (2b) the verb shows an additional number marking (that of the object parcel) and the nominal parcel bears Case and agreement specification. Finally, (2a) has no marking for transitivity whereas $(2 \mathrm{~b})$ shows marking for transitivity $(\mathrm{a}=[+\mathrm{tr}], \mathrm{u}=[-$ $\operatorname{tr}])$.

(2) a. Ullumi aatsaat puurtugar-si-v-u-q, ... today only parcel-get-IND-[-tr]-3SG

'Only today, he got a parcel...'

(Van Geenhoven 1998: 37)

b. Ullumi aatsaat puurtukka-t tiq-u-a-i, ... today only parcel-ABS.PL get-IND-[+tr]-3SG.3PL

'Only today he got the parcel...'

(Van Geenhoven 1998: 38) 
Second, there are well-known thematic restrictions on the possibility of incorporating nominals. Only patients or themes can incorporate, agents cannot. Consider examples from Onondaga as illustration. As (3b) shows incorporation of the theme beans is possible, whereas as (4b) shows incorporation of the agent louse is not. (3a) and (4a) are the corresponding non-incorporating structures.

(3) a. Ka-hi-hw-i ne?o-hsahe?t-a?.

$3 N-C A U S-A S P$ the-PRE-bean-SUF

b. Ka-hsahe?t-ahi-hw-i.

$3 N$-bean-spill-CAUS-ASP

'The beans spilt.'

(Baker 1988: 87)

(4)
a. H-ate-?se:-? ne?o-tsi?kt-a?.
$3 M S$-REFL-crawl-ASP the-PRE-louse-SUF
b. *H-ate-tsi?kti-?se:-?.
3mS-REFL-louse-crawl-ASP
'The louse crawls.'

(Baker 1988: 89)

Third, only arguments can incorporate, adjuncts generally cannot. The following example is from Southern Tiwa and shows that the adjuncts at night and during the day cannot incorporate. ${ }^{1}$

(5) a. Guahua a ia he po, ka e mohe he aho. work ABS-he at night but sleep at day

b. *Gahua po a ia, ka e mohe aho. work-night ABS-he but sleep-day.

'He works at night, but sleep during the day.'

(Baker 1988: 87)

Fourth, indirect objects cannot incorporate when a direct object is present. The following example is also from Southern Tiwa:

(6) *Ta-hliawra-wia-ban ('u'u-de).

laS/A/A-woman-give-PAST baby-SUF

'I gave the baby to the woman.'

(Baker 1988: 279)

Let us now turn to the semantic properties of INs. The IN always receives low scope. For example, in (7) the sentence cannot mean that there is a particular letter that Juuna didn't receive.

\footnotetext{
${ }^{1}$ Some adjuncts are capable of incorporating. However, we will not go into the details of the adjuncts in question. The reader is referred to Mathieu 2004 for a comparison of the properties of adjunct INs and adjunct SNs.
} 
(7) Juuna Kaali-mit ataatsi allagar-si-nngi-1-a-q. Juuna-ABS Kaali-ABL a-INST-SG letter-receive-NEG-IND-[-tr]-3SG 'Juuna didn't receive a letter.'

'It is not the case that Juuna received a letter.'

\# 'There is a letter that Juuna didn't receive.' (Van Geenhoven 1998: 5)

Second, no partitive reading is available with INs. In order to obtain a partitive reading a non-incorporating variant is necessary.

(8) Jensi manni-tu-ssa-a-q.

Jensi-ABS egg-eat-FUT-IND-[-tr]-3SG

\# 'Jensi will eat an egg/some particular eggs.'

Third, INs cannot be used as anaphoric expressions.

(9) a. Qaammatit qassiit matuma siortinagut Juuna months several of.this before Juuna-ABS

puurtukka-nik allakka-nil-lu nassip-p-a-ra parcel-INST letter-INST.PL_and send-IND_[+tr]-1SG.3SG 'Several months ago, I sent a parcel $\mathrm{i}_{\mathrm{i}}$ and some letters.'

b. Ullumi aatsaat puurtugar-si-v-u-q, ... today only parcel-get-IND-[-tr]-3SG

(i) 'Only today he got a parcel $\mathrm{i}_{i}, \ldots$ '.

(ii) \# 'Only today he got the parcel ${ }_{i}, \ldots$ '. (Van Geenhoven 1998: 37)

As shown by Van Geenhoven (1998), if one wants to use a nominal expression to pick up the parcel mentioned, one has to use an NP in a transitive, i.e. a non-incorporating configuration. This is illustrated in (10).

(10) Ullumi aatsaat puurtukka-t tiq-u-a-i. today only parcel-ABS.PL get-IND-[+tr]-3SG.3PL

'Only today he got the parcel $_{i}, \ldots$... (Van Geenhoven 1998: 38)

In conclusion, these semantic and discourse properties suggest that an IN introduces a new variable (at least in West Greenlandic, there are parametric variations; see Mithun 1984). Further evidence for such a view comes from the fact that incorporate nominals are possible in existential constructions. In fact, with the existential predicate, incorporation is compulsory in West Greenlandic.

(11) a. Nillataartarfim tallima-nik manne-qar-p-uq. fridge-LOC five-INST.PL egg-have-IND-[-tr]-3SG 'There are five eggs in the fridge.' 
b. Festi-mi qallunaar-passua-qar-p-u-q. party-LOC white.man-many-have-IND[-tr]-3SG 'There were many Danes (lit. white men) at the party.'

(Van Geenhoven 1998: 27)

It is clear from existential contexts that the $\mathrm{SN}$ in a split construction is nonspecific. As has been shown by Milsark (1977), Heim (1987), Keenan (1987) and McNally (1992), so-called strong/definite quantifiers cannot combine with the existential predicate (unless they denote a kind as in There is every *(kind of) animal in that zoo; see McNally 1998):

(12) a. *There is every book on the table.

b. *There is the book on the table.

c. There is some book on the table.

d. There is a book on the table.

This closes the discussion about syntactic and semantic properties of INs. In the next section we turn to SNs in discontinuous structures.

\section{The Syntactic and Semantic Properties of SNs}

The syntactic and semantic properties described for INs in the previous section are also found with SNs in combien constructions. First, no object agreement is available on the verb when a split variant is used whereas when movement of the nominal is instantiated agreement is possible (in some, not all variants of French).

(13) a. Combien as-tu ouvert de boites? how-many have-you opened of boxes

b. Combien de boites as-tu ouvertes? how-many of boxes have-you opened-FEM.PL 'How many boxes have you opened?'

Second, splitting of the nominal is not possible when an agent is involved, as shown by (14a). On the other hand, when a theme subject is involved there is no problem, as illustrated by (15a). The non-split alternatives are also given.

(14) a. *Combien ont rigolé de personnes? how-many have laughed of persons

b. Combien de personnes ont rigolé ? how-many of persons have laughed 'How many people laughed?' 
(15) a. Combien sont arrivé de personnes? how-many are arrived of persons

b. Combien de personnes sont arrivées? how-many of persons are arrived 'How many people arrived?'

Third, when an adjunct rather than an argument is involved, splitting of the nominal is not possible (at least with some adjuncts; see Mathieu 2004 for details).

(16) a. *En combien as-tu fini ta thèse d'années ? in how-many have-you finished your thesis of-years

b. En combien d'années as-tu fini ta thèse ? in how-many of-years have-you finished your thesis 'How many years did it take you to finish your thesis?'

Fourth, as in the case of INs described in the previous section, SNs that are indirect objects can incorporated only when no direct object is present. (17a) is possible, but (18a) is really bad.

(17) a. Combien as-tu donné de livres à Jean ? how-many have-you given of books to Jean

b. Combien de livres as-tu donné à Jean ? how-many of books have-you given toJean 'How many books have you given to Jean?'

(18) a. *A combien as-tu donné un livre de personnes? to how-many have-you given a book of persons

b. A combien de personnes as-tu donné un livre? to how-many of persons have-you given a book 'To how many people have you given a book?'

For sake of completeness, we show that stranding of indirect objects is possible when no direct object is present. This is illustrated in (19a).

(19) a. A combien as-tu souri de personnes ?

to how-many have-you smiled of persons

b. A combien de personnes as-tu souri ? to how-many of persons have-you smiled 'To many people have you smiled?'

Now that we have reviewed the syntactic properties of SNs, let us turn to their semantic properties. First, SNs always take narrow scope. Whereas in (20b) wide scope of maisons over the modal is possible, this is impossible in (20a). 
(20) a. Combien veux-tu acheter de maisons ?

how-many wants-you to-buy of houses

'How many houses do you want to buy?'

'How many houses (any of them) you want to buy?'

\#'There are houses you want to buy, how many of them do you want to buy?'

b. Combien de maisons veux-tu acheter?

how-many of houses wants-you to-buy

'How many houses do you want to buy?'

?'How many houses (any of them) you want to buy?'

'There are houses you want to buy, how many of them do you want to buy?'

Second, SNs, like INs, are not compatible with a partitive reading. This was first noticed by Obenauer (1994:193). (21a) is odd because we have forced a partitive reading by choosing a possessive DP.
a.?*Combien as-tu lu de mes articles?
how-many have-you read of my articles
b. Combien de mes articles as-tu lus?
how-many of my articles have-you read-MAS-PL
'How many of my articles have you read?'

Third, in situ de-phrases can clearly appear in existential contexts, indicating that they introduce a new discourse referent. The following is a mini-corpus consisting of a series of examples taken from the Web after a search on Google. It is interesting to see that in existential contexts splitting of combien from the nominal with which it is normally associated is much more widespread on the Web than non-splitting.

(22) a. Combien y a-t-il de centres de la petite enfance en Ontario ? how-many there is of centers of the small childhood in Ontario 'How many infancy centres are there in Ontario?' http://www.ontarioearlyyears.ca/oeyc/fr/Questions/howMany.htm

b. Combien y a-t-il de polluants dans un béluga? how-many there is of polluants in a beluga 'How many polluants are there in a beluga?' http:/ / www.baleinesendirect.net/FSC.html?sct=2\&pag=2-1-3.html

c. Combien y a-t-il d'atomes dans l'univers ? how-many there is of-atoms in the-universe 'How many atoms are there in the universe?' http://www.dstu.univmontp2.fr/GRAAL/perso/magnan/dixpuissance80.html 
d. Combien y a-t-il de langues différentes surTerre? how-many there has-it of languages different on Earth 'How many different languages are there on Earth?' http://www.cybersciences.com/Cyber/2.0/Q7627.asp

e. Combien y a-t-il de Chines ? how-many there is of Chinas 'How many Chinas are there?' http://www.warc.ch/up014/14-f.html

f. Combien y a-t-il de débris en orbite autour de la Terre ? how-many there are of debris in orbit around of the Earth 'How many are debris in orbit around the Earth are there?' http://www.cybersciences.com/Cyber/2.0/Q2768.asp

g. Combien y a-t-il de fumeurs au Canada? how-many there are of smokers in Canada 'How many smokers are there in Canada?' http://www.hcsc.gc.ca/hecssesc/tabac/recherches/esutc/trends/how_many. html

h. Combien y a-t-il d'abonnés aux offres Télévision UPC? how-many there have of-subscribers totheoffers Television UPC 'How many subscribers to the offers Television UPC are there?' http://www.upcfrance.com/services/television/questions/q_0000000616.sht $\mathrm{ml}$

i. Combien y a t-il de travailleurs autonomes? how-many there have of workers autonomous 'How many autonomous workers are there?' http://strategis.ic.gc.ca/epic/internet/insbrp-rppe.nsf/fr/rd00697f.html

j. Combien y aura-t-il de coupures de billets en euros ? how-many there will be of bank notes in euros 'How many bank notes in euros will there be?' http://www.euro-institut.org/Reponses.htm

k. Combien y avait-il de robocops à Genève pendant le G8 ? how-many there was of robocops in Geneva during the G8 'How many robocops were there in Geneva during the G8 meeting?' http://www.quellesconnes.com/ anti-g8//breve.php3?id_breve $=142$

1. Combien il y avait de faux lee harvey oswald ? how-many there was of false lee harvey oswald 'How many false Lee Harvey Oswalds were there? http://www.jfk-fr.com/fil_401-0.php

It must also be noted that the in-situ alternative is most natural when the nominal is interpreted as a kind (let us suppose that in this case the variable introduced by the nominal is bound by a Generic operator). 


\section{(23) Combien existe-t-il de types de porphyrie ? how-many exists-it of types of porphyria 'How many types of porphyria exist?' http://www.porphyria-europe.com/FR/00-Info_Patients/question-03.asp}

In conclusion, I would like to claim that split combien de constructions in French are parallel to the following West Greenlandic examples where the WH-phrase 'how many' has raised to a sentence-initial position and the nominal with which the WH-phrase is associated has literally incorporated into the verb:
a. Qassi-nik qimmi-qar-p-i-t?
how-many.INST.PL dog-haveINTER-[-tr]-2SG
'How many dogs do you have?'
b. Qassi-nik aalisaga-tur-p-i-t?
how-many.INST.PL fish-eat_INTER-[-tr]-2SG
'How many fish have you eaten?' (Van Geenhoven 1998: 20)
The aim of the present section was to compare the syntactic and semantic properties of INs with those of SNs in split constructions. In the next section, the discourse properties of both INs and SNs is the focus of attention. The discussion will lead us to section 5 where a formal account of SNs is given.

\section{The Discourse Properties of INs and SNs: A Comparative Analysis}

\subsection{The Case of Noun Incorporation}

Before we begin, it must be stressed that there are several types of noun incorporation languages, and that the pragmatics of the phenomenon varies from one language to another. For example, Mithun (1984) divides noun incorporation (henceforth, NI) languages into four groups according to functional criteria. Type I NI is found in Oceanic, Mayan, Aborigine, Turkish, and English (to baby-sit) among others. It involves lexical compounding that express conventionalized activities (for example, as pointed out by Mithun, bus money or lunch money are more likely nominal compounds than sock money or screwdriver money). The IN is generic and cannot receive a referential interpretation. If the referent is new, an independent NP must be used.

Type II NI is found in Tupinambá, Blackfoot and Yucatec Mayan. In these languages NI is used to manipulate the case marking of various participants in a sentence, thus it is relevant to the verb and its internal arguments. After NI, 
the direct object slot is left open, and an oblique NP can be promoted to direct object status while the demoted direct object is still present as the IN.

In Type III NI (e.g. Chukchi, Nahuatl and Tanoan), the IN receives a referential interpretation. It can be definite and specific, it can introduce a referent into discourse, and it can function as the antecedent of discourse anaphora. NI is used to background a particular referent, making it less salient in discourse. It appears that West Greenlandic as described by Bittner (1994) and Van Geenhoven (1998) is close to type III, yet differs from those languages belonging to that class, in that in West Greenlandic INs are referential, but cannot be definite. They are always interpreted as non-specific.

Type IV NI functions as a classifier system; a semantically general noun is incorporated by the verb, which remains transitive, and the IN can be modified by a more specific external NP (e.g. Mohawk).

According to Farkas \& de Swart, incorporating constructions are characterized by a special morphosyntax that sets them apart from nonincorporating structures (the assumption is thus different from the one proposed by Van Geenhoven, since according to Van Geenhoven semantic incorporation is much more general process that happens even in the presence of referential determiners). Van Geenhoven's theory of semantic incorporation will be given in full in section 5. (25a) is an example from West Greenlandic and shows literal syntactic incorporation. (25b) is an example from Hungarian, a language that has a special pre-verbal position for objects when they are incorporated. This is the position called 'predicate-operator' or 'pred-op' for short by Szabolcsi (1997). ${ }^{2}$ (25c) is an example from Ponapean, a Micronesian language where a special post-verbal position is used for incorporated objects. (25d) is an example from Maori, a language that uses a special determiner for incorporating structures.

\section{(25) a. Suulut timmisartu-liur-p-u-q. \\ Søren.ABS airplane-make-IND.[-tr]--3SG}

'Søren made an airplane.'

(Sadock 1980: 46)

b. Péter u ságot olvas.

Peter newspaper.ACC reads

'Peter is reading a newspaper.'

(Mithun 1984: 47)

c. I keng-winih-la

I eat-medicine-Comp

'I completed my medicine-taking.'

(Mithun 1984: 48)

\footnotetext{
${ }^{2}$ Szabolcsi (1997) in fact splits the pre-verbal Focus position into PredOp and Focus. The former is the position for the restricted set of quantifiers which appear immediately preverbally (rather than in the Topic or Quantifier positions). It is also the unmarked position for bare object nominals and certain verbal prefixes.
} 
d. He tuna no roto I nga awa a

a eel T.of inside DO the.PL river and

he man no rung I nga maunga

a bird T.of top DO the.PL mountain in the ranges

'There were eels in the river, and birds in the ranges.'

(Chung \& Ladusaw 2004: 49)

A number of languages contain a construction in which a $\mathrm{V}$ and its direct object are simply juxtaposed to form an especially tight bond. The $\mathrm{V}$ and $\mathrm{N}$ remain separate words phonologically; but as in all compounding, the $\mathrm{N}$ loses its syntactic status as an argument of the sentence, and the $\mathrm{VN}$ unit functions as an intransitive predicate. The placement of adverbs reveals the bond between Vs and incorporated objects. To illustrate, note the position of upac in the following Kusaien sentences (Lee 1975). It follows the verb in transitive sentences (26a), but in NI structures, the adverb follows the verb-noun complex (26b).

(26) a. Sah el twem upac mitmit sac.

Sah he sharpen diligently knife the

'Sah is sharpening the knife diligently.'

b. Sah el twetwe mitmit upac.

Sah he sharpen knife diligently

'Sa is diligently knife-sharpening.'

(Mithun 1984: 851)

Despite the differences in the degree of formal cohesion between the constituent stems and the differences in terms of discourse, all nominal incorporation constructions share a number of characteristics. It is worth quoting Mithun (1984) in full on the matter:

In all of them, a V stem and an $\mathrm{N}$ stem are combined to form an intransitive predicate denoting a unitary concept. The compound is more than a description; it is the name of an institutionalized activity or state. The IN loses its individual salience both semantically and syntactically. It no longer refers to a specific entity; instead, it simply narrows the scope of the V. It is thus unaccompanied by markers of definiteness or number, or by demonstratives. [...] Since IN's do not refer to specific entities, these constructions tend to be used in contexts without specific, individuated patients. They may be generic statements; or descriptions of on-going activities, in which a patient has been incompletely affected; or habitual activities, in which the specific patient may change; or projected activities, in which the specific patient is not yet identifiable; or joint activities, where an invididual agent incompletely affects a particular patient; or activities directed at an unspecified portion of mass. (Mithun 1984: 856).

In short, INs are not salient constituents in themselves, whose presence might obstruct the flow of information. They simply ride along with their host Vs. (Mithun 1984: 859). In the turn-taking below from Huahtla Nahuatl a new 
entity is first introduced by a non-incorporated nominal, but once it has been introduced and is thus old information, it is incorporated:

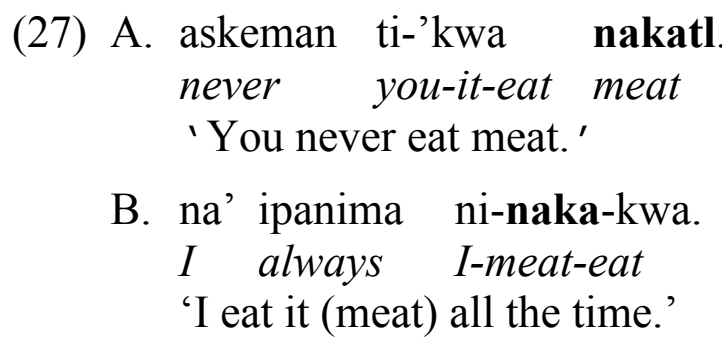

In the same spirit, Dayal (1999) shows for Hindi that nominal incorporation is possible only if the event is relatively frequent and sufficiently distinct from other similar activities. She gives an example like cooking by stirring in a hot pan with a little oil and shows that it has become lexicalized into stir-fry, but that while we can conceptualize an event of cooking an egg by putting it in a pan and placing it on hot car engine we would not expect to see a lexical manner of the verb for such events. According to Dayal, the same is true of noun incorporation. She argues that a form of hidden modality is needed in order to capture the intuition about prototypicality voiced by Mithun (1984). It is thus not a lexical property of a particular verb or nominal whether it can participate in incorporation. Dekhnaa 'to see', for example, incorporates with laRkii 'girl' but not aurat 'woman'. Similarly, bacca 'child' lends itself to incorporating with a verb like sambhaalnaa 'to manage' but not 'to beat'. To paraphrase Dayal, the case is clear with animate objects. laRkii dekhnaa 'girl seeing' cannot be used to describe a situation in which one is sitting by the window watching people to go by, some of whom happen to be girls. Rather, it refers to the act of looking for prospective brides with the purpose of arranging a marriage. There is thus a certain amount of idiosyncrasy typically associated with lexical processes. There is no logical reason that laRkii dekhnaa should be acceptable but not aurat dekhnaa 'woman seeing'.

In the next section, we turn to the discursive behaviour of SNs.

\subsection{The Case of Stranded Nominals}

In this section, a correlation between the patterns noticed by Obenauer (1994) for combien constructions and those that exist in the case of INs is being made. Two things can be said about the semantic properties of SNs. First, they receive what Obenauer (1994) — see also Dobrovie-Sorin (1994) - calls a cardinality reading (interpretation within VP) and what we will call a background topic reading.

As was mentioned at the outset of this paper, according to Obenauer (1994) and Rizzi (2001), the nominal in a combien interrogative is interpreted as specific or D-linked when it raises along with the WH operator. On the other hand, when it remains in situ it is focused and receives a so-called 
cardinality/quantity reading. The fact that SNs can appear in existential constructions suggest that they are focused elements indeed (see the examples introduced in (22)). In addition, it appears that the $\mathrm{SN}$ receives default nuclear stress (cf. Zubizarreta 1998) indicating that the nominal is focused. ${ }^{3}$

(28) Combien as-tu lu DE LIVRES ?

how-many have-you read of books

'How many books have you read?'

The conclusion we reach from these remarks is that the SN introduces a new discourse referent. However, I want to argue that unlike traditional focused constituents the nominal is not salient, i.e. it is not what the sentence is about. In reply to a question such as (29A), du poulet is what the sentence is about. It is in this sense that the constituent du poulet is focused.
A. Qu'est-ce que tu as mangé? what-is-this that you have eaten
'What have you eaten?'

B. J'ai mangé DU POULET.

I-have eaten some chicken

'I have eaten CHICKEN.' (capitalized letters for default stress)

In the case of SNs, however, the nominal is not interpreted as a salient entity. Instead, it is relegated to background information. I would like to suggest that a $\mathrm{SN}$ is an asserted background nominal in the sense of Chierchia \& McConnell-Ginet (2000). Crucially, it is not presupposed, but asserted. This notion will be made more precise below. For the moment, let us examine closely the examples introduced originally by Obenauer (1994) and taken up by Rizzi (2001) that are supposed to show that the in-situ nominal in combien constructions is interpreted as non-specific or non-D-linked. Compare (30a) with $\left(30 a^{\prime}\right)$, (30b) with $\left(30 b^{\prime}\right)$ and (30c) with $\left(30 c^{\prime}\right)$.
a. *ombien de personnes penses-tu qui how-many of persons think-you that-AGR tiennent dans une Twingo ?
hold in a Twingo

a'. ?Combien penses-tu que de personnes tiennent dans une Twingo?

'How many people do you think can fit in a Twingo?'

\footnotetext{
${ }^{3}$ The $[d e \mathrm{~N}]$ constituent can be interpreted contrastively, but this is not what is intended here by capitalizing the constituent in question. What we have in mind is simple default stress.
} 
b. *Combien de torpilles croit-on qui how-many of torpidoes believe-you that-AGR ont coulé le Tirpitz? have sunk the Tirpitz

$\mathrm{b}^{\prime}$.? Combien croit-on que de torpilles ont coulé le Tirpitz ? 'How many do you think sank the Tirpitz?'

c. *Combien de kilomètres crois-tu qui how-many of kilometers believe-you that-AGR séparent Boston de New York? separate Boston from New York

$\mathrm{c}^{\prime}$. ?Combien crois-tu que de kilomètres séparent Boston de New York?

'How many kilometers do you think separate Boston from New York ?'

(Obenauer 1994: 203)

The primed examples are slightly deviant because of the long distance relationship. However, they are much better than the raised WH operator + nominal alternative. The idea, according to Obenauer, is that this is because it makes no sense for the nominal to be interpreted as specific or D-linked. For example, (30a) forces a reading according to which the question is about specific persons and we ask how many of these persons might fit in a Twingo. But the most natural reading this sentence receives is one according to which we do not know the people involved; the question is a general question. It must be said, however, that the non-primed examples have a feel about them that suggests that they are deviant not because they are ungrammatical, but because they are not felicitous. If this is true, this means that the specific versus non-specific dichotomy might not be on the right track, and crucially that it is not a dichotomy that is part of syntax, but of pragmatics. Let us now turn to cases where raising of the nominal is supposedly forced.

According to Obenauer (1994) and Rizzi (2001), in some contexts piedpiping of the nominal together with the WH element is obligatory, because a specific interpretation is forced.

(31) a. ?Combien d'hommes crois-tu qui seraient how-many of-men believe-you that-AGR be-COND capables d'escalader le Mont Blanc? capable of-escalading the Mont Blanc 'How many men do you think could climb the Mont Blanc?' 
b. Combien de personnes veux-tu qui

how-many of persons want-you that-AGR

soient invitées à la fête ?

be-SUBJ invited to the party

'How many people do you want invited at the party?'

c. ?Combien de députés crois-tu qui

how-many of MPS believe-you that-AGR

voteront la motion?

vote-AGR the proposition

'How many MPs do you think will vote the proposition?'

d. ?Combien de journaux crois-tu qui

how-many of newspapers believe-you that-AGR

publieront cette nouvelle?

publish-AGR this news

'How many newspapers do you think will publish this piece of news?'

(Obenauer 1994: 202)

I agree that in these contexts pied-piping of the nominal might be preferred. However, this is more so in (31a) and (31b) than in (31c) and (31d). It is important to stress that the nominal is not presupposed, since an answer to the questions in (31) could in fact all be negative (in the case no one is today capable of climbing the Mont Blanc, the party has been cancelled, the proposition will be rejected by all MPs, it turns out, no newspaper will publish this piece of news, because it is irrelevant, etc.). I suggest that the pied-piped nominal is a topic, but in the sense of foreground or what the sentence is about. In the literature, topic either means 'old', 'presupposed' or 'D-linked' or it means background. I believe that these notions are complementary, i.e. that there are different kinds of topics. In sum, the notion of topic is not a unitary notion. In particular, the distinction between foreground and background is relevant in the case of discontinuous structures.

The contention is that a split combien construction like that in (32a) is most appropriate in a context where the nominal is the focus of attention, the topic under discussion (and of course this may involve a D-linked or partitive context). On the other hand, stranding the nominal is more appropriate in a context where the nominal is not the focus of attention or the topic under discussion. To ask a question such as (32b) is therefore to ask a question, not about specific books, but more about the event of reading.

(32) a. Combien de livres as-tu écrit?

how-many of books have-you written-MAS.PL

www.bataille-des-livres.ch/batlivre/activite/ 2001-

02/atelier/begag/begag03_perso.pdf 
b. Combien as-tu écrit de livres?

how-many have-you written of books

http://felix.cyberscol.qc.ca/LQ/auteurD/dube_jas/entrevue.html

'How many books have you written?'

Imagine a context according to which a speaker $\mathrm{A}$ is asking person $\mathrm{B}$ how many books person B has re-read over the summer? (33a) is clearly about a set of books under the focus of attention while in (33b) the focus of attention is not a set of books. Rather, the sentence is asking about the event of re-reading books.

(33) a. Combien de livres as-tu relus l'été dernier? how-many of books have-you reread the-summer last

b. Combien as-tu relu de livres l'été dernier? how-many have-you reread of books the-summer last 'How many books have you re-read last summer?'

The interpretation obtained in (32b) and (33b) resembles the interpretation that one gets with in-situ interrogatives in French (Boeckx 1999; Chang 1997; Cheng \& Rooryck, 2000; Mathieu 1999, 2004; Zubizarreta \& Vergnaud 2003).

The interpretive divide is very clear in the following attested example. Whereas (34a) is about the event of adopting rats, (34b) is about rats.
a. Combien adopter de rats ?
how-many adopt-INFIN of rats
'How many rats should one adopt?'
http://lerafu.free.fr/combien.html
b. Combien de rats adopter?
how-many of rats adopt-INFIN
'How many (of the) rats should we adopt?'

We can extend to SNs Mithun's (1984) thesis according to which the primary function of noun incorporation is the manipulation of discourse structure and the expression of a conventionalized activity or the background of a given referent. Noun incorporation and nominal stranding thus leads to a thetic statement in the sense of Kuroda (1972) (see also Sasse 1987 and Ladusaw 1994). In-situ interrogatives are thus what we might call thetic questions: they are about an event, not about an entity (the idea of a thetic question is novel, but the thetic versus non-thetic distinction is of course well-motivated). Thetic statements assert, but not presuppose the existence of the object talked about. A prototypical example of a thetic sentence is the so-called presentational construction in French, as shown in (35). 
(35) Y a Jean qui est arrivé en retard. there is Jean that-AGR is arrived late

'Jean arrived late.'

(35) is not about Jean, but about the event of Jean coming. (35) contrasts with (36), a categorical statement, which is about an individual, namely Jean.

(36) Jean est arrivé en retard.

Jean is come late

'Jean arrived late.'

In sum, the idea is that SNs are new topics. They are like shifted topics (in the sense of Aissen 1992), in that they are not given, yet differ from them in that they are not what the sentence is about. They thus share with continuing topics (again in the sense of Aissen 1992) the property of being minus aboutness. Table 1 summarises the differences between shifted, continuing and new topics:

\begin{tabular}{|l|c|c|c|}
\hline & New & Old & Aboutness \\
\hline $\begin{array}{l}\text { Shifted } \\
\text { topics }\end{array}$ & + & - & + \\
\hline $\begin{array}{l}\text { Continuing } \\
\text { topics }\end{array}$ & - & + & - \\
\hline New topics & + & - & - \\
\hline
\end{tabular}

Table 1

The concept of new topic is extremely closed to that of lower-order topic (cf. Sasse 1984). Lower-order topics are non-prominent entities (backgrounded elements), whereas higher-order topics are prominent (foregrounded elements). Whereas foregrounding highlights the most important information in the sentence (this notion is thus close to that of theme), background information means the less important information under discussion. It is not necessarily old or presupposed or given, and not necessarily unstressed.

In the next section, a formal account of SNs is given. We give a semantic interpretation to this kind of nominals and argue in particular that the variable they introduce is interpreted below an event variable. This will account for the scope effects noticed in connection with INs and SNs. These scope effects are part of the semantics rather than the pragmatics of these constructions.

\section{A Formal Account}

\subsection{The Semantics}

The aim of the present section is to first briefly review the previous analyses of semantic incorporation and secondly to give an alternative account. Let us 
begin with Van Geenhoven's theory of semantic incorporation, which is perhaps the best-known analysis of semantic incorporation.

Van Geenhoven's hypotheses are the following: (i) the IN does not introduce a variable; (ii) neither does it introduce a discourse referent; (iii) the noun denotes only a property $\mathrm{P}$ that is absorbed by the predicate and that restricts the argument's variable. This variable denotes, not an individual (type $e$ ), but a property (type $<e, t>$ ); (iv) the nominal receives an existential interpretation from the verb. The incorporating verb: (i) introduces a variable corresponding to the internal argument; (ii) introduces a discourse referent; (iii) provides an existential quantifier; existentially binds the argument's variable; incorporates the property denoted by the predicative indefinite $(=$ semantic incorporation).

In other words, INs are indefinites that are 'co-predicates' of the verb (see also Dobrovie-Sorin 1997; Dobrovie-Sorin \& Laca 1998; Laca 1996; McNally 1995, 1998, for the same hypothesis applied to Romance languages). Since the existential interpretation of a predicative indefinite comes from the verb, this allows the distinction between constructions such as the one as (37a) versus (37b).

(37) a. French people eat snails.

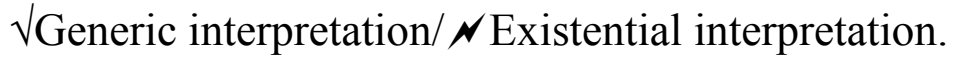

b. French people ate snails.

$N$ Generic interpretation $/ \sqrt{ }$ Existential interpretation.

According to Van Geenhoven, there are in fact three different types of verbs: (i) intrinsically incorporating verbs (existential verbs, cf. McNally 1998; McNally \& Van Geenhoven 1997); (ii) verbs that are never incorporating (psychological verbs, I hated lawyers cannot receive an existential interpretation); (iii) ambiguous verbs (e.g. eat).

Van Geenhoven's analysis is purely semantic in that she argues that all narrow scope indefinites are semantically incorporated regardless of the morpho-syntax involved. According to her, not only nouns in incorporating languages are incorporated, but so are bare plurals in Germanic languages, discontinuous topics in German and weak indefinites in sentences like Everyone read a book when interpreted under the scope of the universal quantifier. This means that, on her view, nominal incorporation is possible even in the presence of a referential determiner.

To recap, the IN is not interpreted like an argument. It is absorbed by the verb as the predicate of the argument's variable corresponding to the internal argument. (38a) shows the lexical entry for a transitive, non-incorporating verb, whereas (38b) shows the lexical entry for an intransitive, incorporating verb. 


$$
\begin{aligned}
\text { (38) a. } & \lambda \mathrm{y} \lambda \mathrm{x}[\operatorname{Verb}(\mathrm{x}, \mathrm{y})] \\
\text { b. } & \left.\lambda \mathrm{P}_{<\mathrm{e}, \triangleright} \lambda \mathrm{x}_{\mathrm{e}} \exists \mathrm{y}[\operatorname{Verb}(\mathrm{x}, \mathrm{y})] \wedge \mathrm{P}(\mathrm{y})\right]
\end{aligned}
$$

The crucial element in Van Geenhoven's analysis is the change of the verb's type: the incorporating verb takes a property as an argument. The verb is thus a second-order predicate (first-order verbs are intransitive verbs like sleep, run). Importantly, on this analysis, the property saturates one of the predicate's arguments.

There are many problems with Van Geenhoven's analysis. One particularity of West Greenlandic is to have a limited series of incorporating verbs. However, this is not the case in other languages (e.g. Hungarian). Besides, some verbs in West Greenlandic also have some transitive uses, that is non-incorporating uses. Since Van Geenhoven rejects the transformational analysis of nominal incorporation (cf. Baker 1988), she must postulate a lexical ambiguity for these verbs, which means we end up with lexical reduplication (this argument is made by Cohen 1999). ${ }^{4}$ This is problematic for languages like Hungarian where the amount of verbs that allow nominal incorporation is much larger than in West Greenlandic (cf. Farkas \& de Swart 2004).

Second, Cohen (1999) also notes that Van Geenhoven's analysis does not account for the fact that singular indefinites seem to always have wider scope than bare plural nominals (cf. Carlson 1977).

(39)a. A dog was everywhere.

Wide scope for $a d o g$

$a^{\prime}$. Dogs were everywhere.

Low scope for $d o g s$

b. An accident happened today three times. Wide scope for an accident

$\mathrm{b}^{\prime}$. Accidents happened today three times. Low scope for accidents

c. Max killed a rabbit for three hours.

Low scope for a rabbit

$c^{\prime}$. Max killed rabbits for three hours.

Low scope for rabbits

Farkas \& de Swart (2004) develop an account that allows a distinction between incorporation of singular and plural bare nouns and that is capable of accounting for the contrasts described in (39).

Third, given that the property introduced by the IN saturates the relevant argument of the predicate, it is difficult to account for examples in which the IN is modified by an adjective.
Esta nutaa-mik
aalisagar-si-v-u-q.
Esta-ABS fresh-INST.SG fish-buy-IND-[-tr]-3SG

'Ester got fresh fish.'

(Van Geenhoven 1998:18)

\footnotetext{
${ }^{4}$ According to Van Geenhoven (1998), INs are base-generated in the position they surface in.
} 
The problem is that the adjective and the IN are both predicates of the same variable: at the point of the concatenation of the verb and the nominal, the predicate is saturated when it comes to the variable corresponding to the theme. Then, it is impossible to continue the semantic interpretation and to compose the verb (and the incorporating nominal) with the adjective.

The tentative solution Van Geenhoven proposes relies on a recomposition strategy according to which the complex verb (verb + incorporated verb) is decomposed, then recomposed. The idea is that we have to go one step back in the Logical Form. Before the incorporation of the nominal, the principle consists in modifying the semantic type of this nominal: from type $<e,\langle e, t>>$ (it is a property), the noun becomes type $<<e, t>,\langle e, t>>$ (which is the type of modified elements). In parallel the verb changes its type so that it is compatible with the new type of its modified argument. This operation is rather costly and it is not even clear that such a backtrack operation is desirable in the grammar or even possible. For example, what consequences would it have for compositionality? How would it be constrained? (see Chung \& Ladusaw 2004 for a critique).

Fourth, according to Dayal (1999), the syntactic visibility of the IN in Hindi makes it difficult to locate the existential quantifier in the lexical component. As the examples in (25) show there seems to always be a syntactic effect associated with nominal incorporation. For instance, as we have seen, some languages use a special pre-verbal position, while others use a special post-verbal position.

Another problem for Van Geenhoven's account concerns the phenomenon of 'doubling' (Mithun 1984). Doubling is when the IN is doubled by a DP. The following example is from Chamorro.

(41) Gäi-ga'

un ga'lagu ennao na patgun.

AGR.have-pet a dog that $L$ child

'That child has a pet dog.' $\quad$ (Chung \& Ladusaw 2004: 124)

In (41b), the predicate is the existential verb gäi and the IN is $g a$ ' 'pet'. The doubled NP is ga'lagu 'dog'. Doubling of this sort has an effect that resembles the one obtained in the following two English examples.

(42) a. Mary is newspaper-reading the Times.

b. John pet-has a dog.

Chung \& Ladusaw (2004) - like Farkas \& de Swart (2004) - argue that the additional noun is an argument and not an adjunct. If the doubled nominal is indeed an argument, then the problem for Van Geenhoven is that the property denoted by the IN saturates the predicate. The latter is no longer available for further composition. Thus, doubling remains unaccounted for under such an analysis. However, if the added nominal is an adjunct, then the problem 
disappears. For example, Carlson (2003) argues that in Mohawk the additional NP is not an argument, but an adjunct and that the construction is rather rare.

Finally, I would like to add that ideally it is best to stick to a classical account of indefinites where indefinites introduce an existential quantifier. This means that the idea that indefinites introduce a variable $\grave{a}$ la Heim or a property $a$ la Van Geenhoven should be abandoned. In addition, type-shifting, which is a costly operation, and flexible-type theory in general should be dispensed with. As we will demonstrate an event semantics and indefinites as existential quantifiers together with a predicate logic with anaphora (à la Dekker 2002) can do all the work. We will sketch such a classical view of indefinites and its possible extension to INs below, but before that let us continue with the various accounts of semantic incorporation that are available in the literature. The reason for this comparison of analyses is to gradually introduce our own account and to get to the heart of the matter, event semantics.

Formally, Dayal proposes like Van Geenhoven (1998) that initially the IN denotes a property $(<e, t>)$. However, whereas Van Geenhoven postulates ambiguity of the verb (incorporating verb versus non-incorporating verb), Dayal proposes that via type-shifting the noun comes to denote an entity of type $e$. The type of the verb is thus maintained constant. Dayal further proposes that in incorporating structures the theme is suppressed (this explains why an incorporating noun does not introduce a discourse referent in Hindi). In order to account for the prototypicality mentioned above she introduces an implicit modality in the semantic representation: the event must receive a particular interpretation, namely the description of a routinized event. (43a) is the logical representation for a non-incorporating verb whereas (43b) is the representation for an incorporating verb.

$$
\begin{aligned}
& \text { a. } \lambda \mathrm{x} \lambda \mathrm{y} \lambda \mathrm{e}[\mathrm{V}(\mathrm{e}) \& \mathrm{Ag}(\mathrm{e})=\mathrm{y} \& \mathrm{Th}(\mathrm{e})=\mathrm{x}] \\
& \text { b. } \lambda \mathrm{P}_{<\mathrm{e}, \mathrm{t}} \lambda \mathrm{y} \lambda \mathrm{e}[\mathrm{P}-\mathrm{V}(\mathrm{e}) \& \mathrm{Ag}(\mathrm{e})=\mathrm{y} \& \operatorname{Appropriately-Classificatory}(\mathrm{e})]
\end{aligned}
$$

The interesting components of Dayal's analysis is that she introduces an event variable in the semantic representation. This allows a proper account of the thetic feel to incorporating structures (and for us of stranded elements as well). However, like Van Geenhoven, the IN denotes a property and the account relies on flexible-types. The difference with other competing analyses of semantic incorporation is that Dayal argues the theme is suppressed.

Chung \& Ladusaw (2004) propose two modes of composition of predicates with their arguments, Restrict and Specify, the first of which is new. Restrict has the particularity of modifying one of the arguments of the predicate without saturating it. This means that the argument in question is available for a further mode of composition, namely Specify. On this view, the doubling phenomena discussed above can be easily accounted for (see example (41)). 
Like other analyses, a nominal starts by denoting a predicate of type $<e, t>$. Of course, there is incompatibility of types when a predicate selects a argument of type $e$. In this case, the operation Specify together with choice functions applies. The use of choice functions implies a type shift. The choice function takes an expression of type $<e, t>$ to return an expression that corresponds an expression of type $e(\mathrm{FA}=$ Function Application).

(44) FA ( $\left.\left.\lambda x \lambda e\left[\operatorname{bark}^{\prime}(x)(e)\right]\right), \mathrm{CF}\left(\left[\operatorname{dog}^{\prime}(y)\right]\right)\right)$

$$
\left.=\exists f \exists e\left[\operatorname{bark}^{\prime}\left(f\left(\operatorname{dog}^{\prime}\right)(e)\right)\right]\right)
$$

We get to the last part of the interpretation after the existential closure of the event variable and of the functional variable. Specify saturates the argument on which it operates. The lambda index is gone and thus the argument is no longer available for another mode of composition. Note that the function is existentially closed above the event.

As for Restrict, the idea is that the variable that corresponds to the theme is restricted by the property for this variable. This means that the variable in question is always bound by a lambda, although there is a change in the position of the lambda operator, this to signal that the argument has been operated on by concatenation. Next, the operator lambda is eliminated by an existential quantifier that binds the variable in question. To illustrate, consider the following example, $d o g$ is a noun that denotes a property and that composes with the predicate feed by Restrict and John is an expression that denotes an entity.

(45) a. John dog-fed.

b. $\mathrm{FA}\left(\operatorname{Restrict}\left(\lambda y \lambda x \lambda e\left[\mathrm{feed}^{\prime}(y)(x)(e)\right], \operatorname{dog}^{\prime}\right), \mathrm{j}\right)$

$=\mathrm{FA}\left(\lambda x \lambda y \lambda e\left[\operatorname{feed}^{\prime}(y)(x)(e) \wedge \operatorname{dog}^{\prime}(y)\right], \mathrm{j}\right)$

$=\lambda y \lambda e\left[\operatorname{feed}^{\prime}(y)(\mathrm{j})(e) \wedge \operatorname{dog}^{\prime}(y)\right]$

(46) a. $\operatorname{EC}\left(\operatorname{EC}\left(\lambda y \lambda e\left[\operatorname{feed}^{\prime}(y)(\mathrm{j})(e) \wedge \operatorname{dog}^{\prime}(y)\right]\right)\right)$

b. $=\exists e \exists y\left[\operatorname{feed}^{\prime}(y)(\mathrm{j})(e) \wedge \operatorname{dog}^{\prime}(y)\right]$

As for the scope of INs versus non-incorporated nominals, INs receive a wide scope because a choice function is existentially quantified (Chierchia 2001; Matthewson 1999; Reinhart 1998; Winter 1997). For INs, one must note that once one arrives at the argument's variable, all the arguments of the predicate that have not been saturated must be existentially closed. The argument $y$ is existentially closed under the scope of the event scope. Since the nominals introduced by the mode of composition restrict are existentially closed under the event, they automatically receive low scope.

I would like to build on Chung \& Ladusaw's (2004) proposal and adopt their idea that in an incorporating structure the argument variable is interpreted above the argument's variable corresponding to the theme. To illustrate, in the 
following example, $x$ corresponds to un homme (a man) and $y$ to a number of books.

$$
\begin{aligned}
& \text { a. } \lambda \mathrm{x} \lambda \mathrm{e} \lambda \mathrm{y}[\operatorname{Verb}(\mathrm{x}, \mathrm{y})(\mathrm{e}) \wedge \mathrm{P}(\mathrm{y})] \\
& \text { b. } \rightarrow \exists \mathrm{x} \exists \mathrm{e} \exists \mathrm{y}[\operatorname{Verb}(\mathrm{x}, \mathrm{y})(\mathrm{e}) \wedge \mathrm{P}(\mathrm{y})] \\
& \text { c. Combien un homme a-t-il lu de livres? } \\
& \text { how-many a man has-he read of books } \\
& \text { 'How many books has a man read?' }
\end{aligned}
$$

Note that event variable, which has been introduced as part of our ontology, is existentially quantified. This is the option for cases where the discontinuous structure is interpreted neither generically or habitually. We can take this case as the default case. When the structure is interpreted generically, the event variable is bound by a generic operator (this is the analysis for the example in (23)).

$$
\begin{aligned}
& \text { (48) } \exists \mathrm{xGENe} \exists \mathrm{y}[\mathrm{Verb}(\mathrm{x}, \mathrm{y})(\mathrm{e}) \wedge \mathrm{P}(\mathrm{y})] \\
& \text { Combien existe-t-il de types de porphyrie? } \\
& \text { how-many exists-it of types of porphyria } \\
& \text { 'How many types of porphyria exist?' } \\
& \text { http://www.porphyria-europe.com/FR/00-Info_Patients/question-03.asp }
\end{aligned}
$$

In the case where the discontinuous construction is associated with a habitual reading ('habitual' indicates that the action is repeated on a number of occasions, or is performed on a regular basis), the event variable is bound by a habitual operator (a kind of frequency adverb).

$$
\begin{aligned}
& \exists \mathrm{xHABe} \exists \mathrm{y}[\mathrm{Verb}(\mathrm{x}, \mathrm{y})(\mathrm{e}) \wedge \mathrm{P}(\mathrm{y})] \\
& \text { Combien lis-tu de livres pendant les vacances d'été? } \\
& \text { how-many read-you of books during the holiday of-summer } \\
& \text { 'How many books do you read during the summer holiday?' }
\end{aligned}
$$

As argued by Van Geenhoven (1998), semantic incorporation is impossible with some predicates - for example, psychological verbs and predicates such as quite common and rare. By way of illustration, the example in (48a) can only be interpreted generically; it cannot receive an existential interpretation. (48b) and (48c) show that existentials such parts of this machine and dogs that are sitting here cannot combine with individual-level predicates like quite common and rare.

(50) a. I hate/hated lawyers.

b.??Parts of this machine are quite common.

c.??Dogs that are sitting here are rare.

It must be noted that semantic incorporation is not impossible with all individual-level predicates. By definition, individual-level predicates describe 
permanent properties or properties that independent of the context. Following Carlson (1977), Chierchia (1995) distinguishes between three types of individual level predicates: (i) psychological verbs like love, hate, adore; (ii) nominal predicates such as to be a mammal, to be a doctor or to have blue eyes; (iii) adjectival predicates such as to be intelligent, to be tall or to be blond. Incorporation in West Greenlandic appears to be impossible with (i), but possible with (ii).

Of particular interest to us is that some individual-level predicates are odd with split combien constructions while others are perfectly OK. In this respect, we differ from Obenauer's (1994) claim according to which individual-level predicates are all fine with split combien constructions.

(51) a. Combien le critique a-t-il apprécié de films ? how-many the critic has-he appreciated of films 'How many films has the critic appreciated?'

b. Combien a-t-il possédé de tableaux ? how-many has-he own of paintings 'How many paintings has he owned?'

(Obenauer 1994: 129)

The following two examples are attested examples.

(52) a. Combien possedez vous de dvd? how-many own you of $d v d$ 'How many DVDs do you own?' http:// forum.rue-montgallet.com/ruemontgallet/DVD/sujet-23-1.htm

b. Combien possèdes-tu d'appareils différents how-many own-you of-machines different pour écouter de la musique ? for listen-INF of the music www.esigge.ch/primaire/2-objets/3musique/ 4complem/0complement.htm

Splitting is odd, however, with predicates like préférer 'prefer' or connaître 'know', as shown in (53a) and (53b).

(53) a.?*Combien connais-tu de langues? how-many know-you of languages

a' Combien de langues connais-tu ? 'How many languages do you know?'

b.?*Combien préfères-tu de gâteaux ? how-many prefer-you of cakes

b' Combien de gâteaux préfères-tu? 'How many cakes do you prefer?' 
I suggest that these contrasts arise because some, but not all, individual predicates introduce an event variable. In the literature, the term 'event', which Davidson (1980) originally used for the extra event argument in a sentence with an action verb, usually stands in for 'eventuality', which Bach (1986) defined as covering 'states, processes, and events'. On this view, all individual-level predicates introduce an event (of some kind). Another view, that of Kratzer (1989), is that only stage-level predicates, but not individual ones, contain an event variable. The view defended in this paper is thus a kind of a third-way view, where some but not all individual-level predicates introduce an event variable.

Interestingly, the kind of presentational sentences introduced in (35) are impossible with (some) individual-level predicates. This confirms the thetic statement of split interrogatives. The pattern are described for Québec French by Côté (1998).

$$
\begin{aligned}
& \text { a. *Y a Marie qui est intelligente. (no focus on Marie) } \\
& \text { there is Marie that-AGR is intelligent } \\
& \text { 'Marie is intelligent.' } \\
& \text { b. *Y a Jean qui aime Montréal. (no focus on Jean) } \\
& \text { there is Jean that-AGRlove Montréal } \\
& \text { 'Jean loves Montreal.' }
\end{aligned}
$$

Based upon the above facts, Côté (1998) claims that sentences such as those in (54) do not assert the existence of an individual but that of an event, and that the reason why only stage-level predicates are allowed can be accounted for by Kratzer's (1989) hypothesis that only stage-level predicates, but not individual ones, contain an event variable, given the assumption that the existential operator in the existential construction can quantify over either event variables or individual ones. It must be noted, however, that some individual predicates can occur in presentational constructions, as witnessed by (55).

(55) $\mathrm{Y}$ a Jean qui possède plein de DVD.

there is Jean that-AGR owns lots of $d v d$

'Jean owns lots of DVDs.'

Turning now to the semantic representation for the non-incorporating structure, I argue that there is no need for the choice function mechanism postulated by Chung \& Ladusaw. I follow Dekker's (2002) idea that indefinites introduce an existential quantifier as in the classic theory of indefinites. On this view, anaphoric relations are stated in the semantics, hence the name of the proposal Predicate Logic with Anaphora.

(56) a. $\lambda x \lambda y \lambda e[\operatorname{Verb}(x, y)(e)]$

$$
\text { b. } \rightarrow \exists x \exists y \exists e[\operatorname{Verb}(x, y)(e)]
$$


c. Combien de livres un homme a-t-il lu ? how-many of books a man has-he read 'How many books has a man read?'

The present analysis of SNs is very similar to the analysis proposed by Carlson (2003) for incorporated objects. Carlson reduces Diesing's (1992) Mapping Hypothesis, which bears on the syntactic contribution to the semantics partition of quantificational structure, to the semantics. This is achieved by the appeal to event semantics. However, there is a syntactic residue to which we turn in the next section.

\subsection{A Syntactic Residue}

In previous work (Mathieu 2004), I analysed SNs as semantically incorporated à la Van Geenhoven. I argued that the predicate introduced by the stranded indefinite is absorbed by the verb as the predicate of that verb's internal argument's variable. The valence of the verb which incorporates the noun is reduced by one. The transitive sentence becomes intransitive which means that the nominal is dethematized semantically (the theme or patient has been absorbed), and pragmatically, the noun is non-prominent. As noted above in the text, Van Geenhoven's analysis is purely semantic and does not correlate semantic incorporation to morpho-syntactic properties of the objects involved. No attempt on my part was made to motivate a morpho-syntactic correlate to the semantic incorporation analysis of SNs.

However, I have come to notice that there is evidence for the idea that stranding of the nominal has a syntactic effect. Evidence from the placement of adverbs suggests that there is dedicated syntactic position for stranded/incorporated nominals in split constructions. The adverb souvent 'often' can be placed post-verbally, as shown in (57a), or pre-verbally as in $\left(57 a^{\prime}\right)$ - although the second option is irrelevant for us, and is shown only for the sake of completeness - but when the nominal is stranded the adverb can no longer be placed post-verbally, as demonstrated by (57b). The adverb can, of course, also be placed pre-verbally, as shown in $\left(57 b^{\prime}\right)$.

(57) a. Combien de livres as-tu lu souvent? how-many of books have-you read often

$a^{\prime}$. Combien de livres as-tu souvent lus?

b.?*Combien as-tu lu souvent de livres? how-many have-you read often of books

$\mathrm{b}^{\prime}$. Combien as-tu souvent lu de livres ?

'How many books have you often read?' 
We know independently that in French it is perfectly acceptable to have an adverb between the verb and the object, since the verb has raised to Infl (Pollock 1989).

(58) J'ai lu souvent des livres de Zola.
I-have read often some books of Zola
'I have often read Zola's books.'

The fact in (44b) suggests that there is a special postverbal position in French for new topics/INs. In this respect, French resembles Kusaien (recall that in that language a special post-verbal position is used for incorporated objects and that the $\mathrm{V}$ and the $\mathrm{N}$ remain separate words phonologically).

Another possibility is that the nominal has raised higher in the clause to a position adjacent to that of the verb, but that its movement has been masked by verb movement in the $\mathrm{T}$ domain. Suppose the verb is in Tense, then the nominal must be higher than $v \mathrm{P}$ but below Tense (Case-checking has been achieved via a specifier of $v \mathrm{P}$ overtly, via successive movement). If the nominal had remained in its canonical object position, then we would expect an adverb could intervene between the verb and the nominal (Case-checking would in this case be via Agree, and no overt movement would be necessary). The position the SN moves to might be a topic position. However, this topic position must be a different one from the IP extended domain. If this is true, then Belletti's (forthcoming) idea that internal topics are interpreted like external topics must be wrong. Let me explain.

The split-CP hypothesis put forward by Rizzi (1997), and further developed by Poletto (2000), Benincá (2001), and Benincá \& Poletto (to appear), has been very influential in recent years. It pertains to the view that the external area of IP is far richer than presumably thought. Very much in the spirit of Pollock (1989), who split IP in a series of distinct functional projections, the $\mathrm{CP}$ is now decomposed in several layers, one of which being a Focus projection. The Focus projection is unique and topic positions are folded around it. According to Rizzi, topic, unlike focus is recursive: more than one topic can be appear in the sentence and the order of these topic elements is free. On the other hand, Benincá \& Poletto have recently argued that there are dedicated positions for Topic(s) in the left periphery of the clause (e.g. a position for Hanging Topics, one for Left Dislocated topics, etc.). Haegeman (2004) argues that there are differences between Germanic and Romance languages.

Another trend has recently flourished: Belletti (to appear) argues that the area immediately above VP also contains a Focus position surrounded by Topic positions (see also Belletti \& Shlonsky 1995 and Cecchetto 1999). On this proposal, the internal Focus position is associated with a different interpretation from that of the external position (contrastive focus for the external position vs. informational focus for the internal position). On the 
other hand, it is suggested that the topic interpretation is uniform in both peripheries and is assimilated to 'given', 'known', 'non-focus' interpretation.

Based on the French data involving combien constructions and following the logic developed in the last two paragraphs, we might conclude, contra Belletti, that internal topics are interpreted differently from the external ones. However, it remains to be established whether there is indeed a position to left periphery of $v \mathrm{P}$ for the kind of topicalized elements that were described in this paper. This position might correspond to the pre-verbal position found in Hungarian for incorporated elements. But since in Hungarian the verb surely must also like French be raising to the $\mathrm{T}$ domain, the putative masking effect found in French is almost quite possibly on the wrong track, leaving the special postverbal position the only feasible alternative.

One final question that arises is the status of de in split combien constructions. I would like to argue that it is an expletive/deficient determiner and not a referential determiner (see also Heyd 2003 for de $\mathrm{N}$ structures in negative contexts). French SNs have thus the property of both Maori (a special determiner) and Kusaien where a special post-verbal position is used for incorporated objects.

\section{Conclusion}

To conclude, stranded nominals in split constructions share many syntactic and semantic properties with incorporated nominals. They involve a specific post-verbal position, a non-referential determiner, and introduce a variable that is interpreted VP internally/under the event variable. The stranded nominal is an asserted background topic and questions that involve the splitting of a nominal from the operator with which it is normally contiguous are thetic interrogatives: they are about an event, and not about particular entities. It was shown that the notion of specificity or D-linking for the raised nominal is too strong while on the other hand it was argued that the stranded nominal is not a focused element: it does not introduce a foregrounded entity.

\section{References}

Aissen, Judith. 1992. Topic and Focus in Mayan. Language 68: 43-80.

Bach, Emmon. 1986. The Algebra of Events. Linguistics and Philosophy 9: 5-16

Baker, Mark C. 1988. Incorporation: A Theory of Grammatical Function Changing. University of Chicago Press, Chicago.

Belletti, Adriana and Ur Shlonsky. 1995. The Order of Verbal Complements. A Comparative Study. Natural Language and Linguistic Theory 13: 489-526.

Belletti, Adriana. To appear. Aspects of the Low IP area. In Adriana Belletti and Luigi Rizzi, eds., The Cartography of Syntactic Structures, Vol. 3. Oxford University Press, Oxford. 
Benincá, Paola. 2001. Syntactic Focus and Intonational Focus in the Left Periphery. In Guglielmo Cinque and Giampaolo Salvi, eds., Current Studies in Italian Syntax Offered to Lorenzo Renzi. North Holland, Amsterdam, pp. 39-64.

Benincá, Paola and Cecilia Poletto. To appear. Topic, Focus and V2: Defining the CP Sublayers. In Adriana Belletti and Luigi Rizzi, eds., The Cartography of Syntactic Structures, Vol. 3. Oxford University Press, Oxford.

Bittner, Maria. 1994. Case, Scope and Binding. Kluwer, Dordrecht.

Boeckx, Cédric. 1999. Decomposing French Questions. In Jim Alexander, Na-Rae Han and Michelle Minnick Fox, eds., University of Pennsylvania Working Papers in Linguistics 6. Proceedings of the 23rd Annual Penn Linguistics Colloquium, pp. 69-80.

Butler, Alastair and Eric Mathieu. 2004. The Syntax and Semantics of Split Constructions: A Comparative Study. Palgrave, Basingstoke.

Carlson, Greg. 1977. Reference to Kinds in English. Ph.D. diss., University of Massachusetts, Amherst.

Carlson, Greg. 2003. Weak Indefinites. In Martine Coene and Yves D'Hulst, eds., From NP to DP. Vol. 1: The Syntax and Semantics of Noun Phrases. John Benjamins, Amsterdam, pp. 195-210.

Cecchetto, Carlo. 1999. A Comparative Analysis of Left and Right Dislocation in Romance. Studia Linguistica 53: 43-67.

Chang, Lisa. 1997. WH-in-situ Phenomena in French. MA diss., University of British Columbia, Vancouver.

Cheng, Lisa and Johan Rooryck. 2000. Licensing WH-in-situ. Syntax 3: 1-19.

Chierchia Gennaro and Sally McConnell-Ginet. 2000. Meaning and Grammar: An Introduction to Semantics. MIT Press, Cambridge, MA.

Chierchia, Gennaro. 1995. Dynamics of Meaning: Anaphora, Presupposition, and the Theory of Grammar. The University of Chicago Press, Chicago.

Chierchia, Gennaro. 2001. A Puzzle about Indefinites. In Carlo Cecchetto, Gennaro Chierchia and Maria Teresa Guasti, eds, Semantic Interfaces: Reference, Anaphora and Aspect. CSLI, Chicago, pp. 51-89.

Chung, Sandra and William Ladusaw. 2004. Restriction and Saturation. MIT Press, Cambridge, MA.

Cohen, Ariel. 1999. Review of Veerle Van Geenhoven's Semantic Incorporation and Indefinite Descriptions: Semantic and Syntactic Aspects of Noun Incorporation in West Greenlandic. Stanford: CSLI, 1998. Linguistics 37: 739-751.

Côté, Marie-Hélène. 1998. Quantification Over Individual and Events. Proceedings of WCCFL.17: 147-161.

Davidson, Donald. 1980. Essays on Actions and Events. Clarendon Press, Oxford.

Dayal, Veneeta. 1999. Bare NPs, Reference to Kinds, and Incorporation, Proceedings of SALT IX, Cornell Linguistics Club, Cornell University, Ithaca, NY,

Dekker, Paul. 2002. Meaning and Use of Indefinite Expressions. Journal of Logic, Language and Information 11: 141-194.

Dobrovie-Sorin, Carmen. 1994. The Syntax of Romanian: Comparative Studies in Romance. Mouton de Gruyter, Berlin/NewYork.

Dobrovie-Sorin, Carmen. 1997. Classes de prédicats, distribution des indéfinis et la distinction thétique-catégorique. Le Gré des Langues. L'Harmattan, Paris, pp. 58-97.

Dobrovie-Sorin, Carmen and Brenda Laca. 1998. La généricité entre la référence à l'espèce et la quantification générique. Actes de Langues et Grammaires III. Université de Paris 8, pp. 58-97.

Doetjes, Jenny. 1997. Quantifiers and Selection: On the Distribution of Quantifying Expressions in French, Dutch and English. Ph.D. diss., Leiden University. 
Diesing, Molly. 1992. Indefinites. MIT Press, Cambridge, MA.

Farkas, Donca and Henriëtte de Swart. 2004. The Semantics of Incorporation. CSLI, Chicago.

Heim, Irene. 1987. Where Does the Indefiniteness Restriction Apply? Evidence from the Definiteness of Variables. In Eric Reuland and Alice ter Meulen, eds., The Representation of (In)definiteness. MIT Press, Cambridge, MA, pp. 21-42.

Heyd, Sophie. 2003. L'interprétation des Syntagmes Nominaux en des et de en position sujet et objet - Généricité, Habitualité et Incorporation sémantique. Ph.D. diss., Université de Strasbourg 2.

Keenan, Edward. 1987. A Semantic Definition of 'Indefinite NP' In Eric Reuland and Alice ter Meulen, eds., The Representation of (In)definiteness. MIT Press, Cambridge, MA, pp. 286-318.

Kratzer Angelika. 1989. An Investigation of the Lumps of Thought. Linguistics and Philosophy 12: 607-653.

Kuroda, S-Yuki. 1972. The Categorical and the Thetic Judgment. Foundations of Language 9: $153-185$.

Ladusaw, William. 1994. Thetic and Categorical, Stage and Individual, Weak and Strong. In Proceedings of SALT IV: 220-229.

Laca, Brenda. 1996. Acerca de la Semántica de los Plurales Escuetos en Español. In Ignacio Bosque, ed., El Sustantivo sin Determinación. La Ausencia de Determinante en la Lengua Española. Visor, pp. 241-268.

Lee, Kee-Dong. 1975. Kusaien Reference Grammar. University Press of Hawaii, Honolulu.

Mathieu, Eric. 1999. French WH in situ and the Intervention Effect. UCL Working Papers in Linguistics 1: 441-472.

Mathieu, Eric. 2004. The Mapping of Form and Interpretation: The Case of Optional WHmovement in French. To appear in Marco Haverkort, Helen de Hoop and Maurits van den Noort, eds., Variation in Form versus Variation in Meaning: Lingua.

Matthewson, Lisa. 1999. On the Interpretation of Wide-Scope Indefinites. Natural Language Semantics 7: 79-134.

McNally, Louise. 1992. A Semantics for the English Existential Construction. Ph.D. diss., University of California, Santa Cruz.

McNally, Louise. 1995. Bare Plurals in Spanish are Interpreted as Properties. In Glyn Morrill and Richard Oehrle, eds, Formal Grammar. Polytechnic University of Catalonia, Barcelona, pp. 197-212.

McNally Louise. 1998. Existential Sentences without Existential Quantification. Linguistics and Philosophy 21: 353-392.

McNally, Louise and Veerle Van Geenhoven. 1997. Redefining the Weak/Strong Distinction. Paper presented at the 1997 Paris Syntax and Semantics Colloquium. Available here: http://www.upf.es/dtf/personal/louisemcnally/ Accessed 18 May 2004.

Milsark, Gary. 1977. Towards an Explanation of Certain Peculiarities in the Existential Construction in English. Linguistic Analysis 3: 1-30.

Mithun, Marianne. 1984. The Evolution of Noun Incorporation. Language 60: 847-893.

Obenauer, Hans-Georg. 1976. Etudes de Syntaxe Interrogative du Français. Niemeyer, Tübingen.

Obenauer, Hans-Georg. 1983. Une Quantification Non-Canonique: la Quantification à Distance. Langue Française 58: 66-88.

Obenauer, Hans-Georg. 1994. Aspects de la Syntaxe A-barre. Thèse de Doctorat d'Etat, Université de Paris VIII.

Poletto, Cecilia. 2000. The Higher Functional Field: Evidence from Northern Italian Dialects. Oxford University Press, Oxford. 
Pollock, Jean-Yves. 1989. Verb Movement, Universal Grammar, and the Structure of IP. Linguistic Inquiry 20: 364-424.

Reinhart, Tanya. 1998. WH-in situ in the Framework of the Minimalist Program. Natural Language Semantics 6: 29-56.

Rizzi, Luigi. 1990. Relativized Minimality. MIT Press, Cambridge, MA.

Rizzi, Luigi. 1997. The Fine Structure of the Left Periphery. In Liliane Haegeman, ed., Elements of Grammar. Kluwer, Dordrecht. pp. 281-337.

Rizzi, Luigi. 2001. Reconstruction, Weak Island Sensitivity, and Agreement. In Carlo Cecchetto, Gennaro Chierchia and Maria Teresa Guasti, eds., Semantic Interfaces: Reference, Anaphora and Aspect. CSLI, Chicago, pp. 145-176.

Sadock, Jerrold. 1980. Noun Incorporation in Greenlandic: A Case of Syntactic Word Formation. Language 56: 300-319.

Sasse, Hans-Jürgen. 1984. The Pragmatics of Noun Incorporation in Eastern Cushitic Languages. In Frans Plank, ed., Objects: Towards a Theory of Grammatical Relations. Academic Press, London, pp. 243-268.

Sasse, Hans-Jürgen. 1987. The Thetic-Categorial Distinction Revisited. Linguistics 25: 511580.

Swart, Henriëtte de, 1992. Intervention Effects, Monotonicity and Scope. Proceedings of SALT 2. Ohio State University Press, Columbius, pp. 387-406

Szabolcsi, Anna. 1997. Strategies for Scope Taking. In Anna Szabolcsi, ed., Ways of Scope Taking. Kluwer, Dordrecht. pp. 109-154.

Van Geenhoven, Veerle. 1998. Semantic Incorporation and Indefinite Descriptions: Semantic and Syntactic Aspects of Noun Incorporation in West Greenlandic. CSLI, Stanford.

Winter, Yoad. 1997. Choice-Functions and the Scopal Semantics of Indefinites. Linguistics and Philosophy 20: 399-471.

Zubizarreta, Maria-Luisa. 1998. Prosody, Focus, and Word Order. MIT Press, Cambridge, MA.

Zubizarreta, Maria-Luisa and Jean-Roger Vergnaud. 2003. Intervention Effects in the French WH-in situ Construction: Syntax or Interpretation? LSRL, Vol. 1. 